How to Cite

Suleiman, O. M. E., Osman, M. Y., \& Hassan, T. (2019). Validity of finite element method: Analysis of laminated composite decks plates subjected to in plane loading. International Journal of Physics \& Mathematics, 2(1), 1-10.

https://doi.org/10.31295/ijpm.v2n1.53

\title{
Validity of Finite Element Method: Analysis of Laminated Composite Decks Plates Subjected to in Plane Loading
}

\author{
Osama Mohammed Elmardi Suleiman \\ Nile Valley University, Sudan, East Africa \\ Corresponding author email: osamamm64@gmail.com \\ Mahmoud Yassin Osman \\ Kassala University, Sudan, East Africa \\ Tagelsir Hassan \\ Omdurman Islamic University, Sudan, East Africa
}

\begin{abstract}
To verify the accuracy of the present technique, buckling loads are evaluated and validated with other works available in the literature. Further comparisons were carried out and compared with the results obtained by the ANSYS package and experimental results. The good agreement with available data demonstrates the reliability of the finite element method used.

Keywords---finite element, fortran program, laminated decks plates, plane loads, validity.
\end{abstract}

\section{Introduction}

Several numerical methods could be used in this study, but the main ones are finite difference method (FDM), dynamic relaxation coupled with finite difference method (DR), and finite element method (FEM).

In the finite difference method, the solution domain is divided into a grid of discrete points or nodes. The partial differential equation is then written for each node and its derivatives are replaced by finite divided differences. Although such pointwise approximation is conceptually easy to understand, it becomes difficult to apply for a system with irregular geometry, unusual boundary conditions, and heterogeneous composition.

The DR method was first proposed in 1960" ${ }^{\text {th }}$; see Rushton (1968); Cassel \& Hobbs (1966); and Day (1965). In this method, the equations of equilibrium are converted to dynamic equations by adding damping and inertia terms. These are then expressed in finite difference form and the solution is obtained through iterations. The optimum damping coefficient and the time increment used to stabilize the solution depend on the stiffness matrix of the structure, the applied load, the boundary conditions and the size of mesh used (Suleiman, 2017; Arauz et al., 2017).

In the present work, a numerical method known as the finite element method (FEM) is used. It is a numerical procedure for obtaining solutions to many of the problems encountered in engineering analysis. It has two primary subdivisions. The first utilizes discrete elements to obtain the joint displacements and member forces of a structural framework. The second uses the continuum elements to obtain approximate solutions to heat transfer, fluid mechanics, and solid mechanics problem. The formulation using the discrete element is referred to as matrix analysis of structures and yields results identical with the classical analysis of structural frameworks. The second approach is the true finite element method. It yields approximate values of the desired parameters at specific points called nodes. A general finite element computers program, however, is capable of solving both types of problems and the name" finite element method" is often used to denote both the discrete element and the continuum element formulations.

The finite element method combines several mathematical concepts to produce a system of linear and non linear equations. The number of equations is usually very large, anywhere from 20 to 20,000 or more and requires the computational power of the digital computer.

ISSN 2632-9417

Received Jan 20, 2019 / Accepted Jun 18, 2019 / Published Jul 05, 2019 
It is impossible to document the exact origin of the finite element method because the basic concepts have evolved over a period of 150 or more years. The method as we know it today is an outgrowth of several papers published in the $1950^{\text {th }}$ that extended the matrix analysis of structures to continuum bodies. The space exploration of the $1960^{\text {th }}$ provided money for basic research, which placed the method of a firm mathematical foundation and stimulated the development of multi-purpose computer programs that implemented the method. The design of airplanes, unmanned drones, missiles, space capsules, and the like, provided application areas.

The finite element method (FEM) is a powerful numerical method, which is used as a computational technique for the solution of differential equations that arise in various fields of engineering and applied sciences. The finite element method is based on the concept that one can replace any continuum by an assemblage of simply shaped elements, called finite elements with well-defined force, displacement, and material relationships. While one may not be able to derive a closed - form solution for the continuum, one can derive approximate solutions for the element assemblage that replaces it. The approximate solutions or approximation functions are often constructed using ideas from interpolation theory, and hence they are also called interpolation functions. For more details refer to References (Constance et al., 1966; Whitney \& Pagano, 1970; Seloodeh \& Karami, 2004).

In a comparison between the finite element method (FEM) and dynamic relaxation method (DR), Aalami (1972), found that the computer time required for the finite element method is eight times greater than for DR analysis, whereas the storage capacity for FEM is ten times or more than that for DR analysis. This fact is supported by Putcher \& Reddy (1986), Turvey \& Osman (1990, 1989, 1991) and Osama Mohammed Elmardi Suleiman (2014, 2015a, 2015b, 2015c, 2016).

who noted that some of the finite element formulations require large storage capacity and computer time. Hence due to the large computations involved in the present study, the finite element method (FEM) is considered more efficient than the DR method. In another comparison, Vernon (1972), found that the difference in accuracy between one version of FEM and DR may reach a value of more than $15 \%$ in favor of FEM. Therefore, the FEM can be considered of acceptable accuracy. The apparent limitation of the DR method is that it can only be applied to limited geometries, whereas the FEM can be applied to different intricate geometries and shapes (Gamez et al., 2017; González et al., 2017).

\section{Verification of the Computer Program}

Convergence Study: The optimum number of plate elements in the $x$ any $y$ directions (i.e. mesh size or discretization), to be used in order to compute the buckling loads with reasonable accuracy can be obtained by a convergence study. The suitable number of finite elements is determined by a number of factors which include material properties, plate dimensions, lamination scheme, boundary conditions and the storage capacity of the computer ram.

It can be observed that, as the number of modes increases, the number of finite elements required increases. Therefore, it is expected that the higher modes need number of elements.

All of the analyses described in the present thesis have been undertaken to assume the plate to be subjected to identical and/ or different support conditions on the four edges of the plate. The three sets of the edge conditions used here are designated as clamped-clamped (CC), simply - simply supported (SS), clamped - simply supported (CS), are shown in Table 1 below.

Table 1

Boundary conditions

\begin{tabular}{lcc}
\hline $\begin{array}{c}\text { Boundary } \\
\text { Conditions }\end{array}$ & $\begin{array}{c}\text { Plate dimensions in } \\
\mathrm{y}-\text { coordinate } \\
x=0, x=a\end{array}$ & $\begin{array}{c}\text { Plate dimensions } \\
\text { in } \mathrm{x}-\text { coordinate }\end{array}$ \\
\hline $\mathrm{CC}$ & $w=\phi=\psi=0$ & $y=0, y=b$ \\
$\mathrm{SS}$ & $w=\psi=0$ & $w=\phi=0$ \\
$\mathrm{CS}$ & $w=\phi=\psi=0$ & $w=\phi=0$ \\
\hline
\end{tabular}

Table 2 shows the convergence study of non - dimensional buckling load of simply supported SS square isotropic plate with length to thickness ratio $(\mathrm{a} / \mathrm{h}=20)$ having the following material properties: material 1: $E_{y} / E_{x}=1.0, G_{x y} / E_{x}=G_{y z} / E_{x}=G_{x z} / E_{x}=0.4, v_{x y}=0.25$

It could be observed from Table 2 that the values of the buckling parameter $\bar{P}=P b^{2} / E_{2} h^{3}$ converge as the number of elements in the mesh are increased (i.e. as the mesh size is progressively reduced). These results suggest 
that a $6 \times 6$ mesh over the plate is adequate for the present work (i.e. less than $1.32 \%$ difference compared to the finest mesh result available). Therefore, a mesh size of $6 \times 6$ is found to be sufficient to predict the first seven modes of buckthe ling load. In practice only the first three modes of buckling are sufficient.

Table 2

Convergence study of non - dimensional modes of buckling $\bar{P}=P a^{2} / E_{1} h^{3}$ of simply supported (SS) isotropic square plate with $\mathrm{a} / \mathrm{h}=20$. (material 1 )

\begin{tabular}{cccccccc}
\hline Mesh & \multicolumn{7}{c}{ Mode Sequence Number } \\
\cline { 2 - 8 } Size & 1 & 2 & 3 & 4 & 5 & 6 & 7 \\
\hline $2 \times 2$ & 30.69 & 76.89 & 83.18 & 83.49 & 94.71 & 94.95 & 101.78 \\
$3 \times 3$ & 32.64 & 79.12 & 79.18 & 117.58 & 179.04 & 189.78 & 191.05 \\
$4 \times 4$ & 33.60 & 82.38 & 82.44 & 123.22 & 165.70 & 166.35 & 192.53 \\
$5 \times 5$ & 34.10 & 84.08 & 84.14 & 127.71 & 168.69 & 168.92 & 202.10 \\
$6 \times 6$ & 34.39 & 85.10 & 85.15 & 130.85 & 170.41 & 170.52 & 208.35 \\
$7 \times 7$ & 34.58 & 85.75 & 85.79 & 133.03 & 171.55 & 171.61 & 212.50 \\
$8 \times 8$ & 34.70 & 86.19 & 86.23 & 134.57 & 172.34 & 172.39 & 215.79 \\
$9 \times 9$ & 34.78 & 86.50 & 86.53 & 135.68 & 172.92 & 172.97 & 218.07 \\
$10 \times 10$ & 34.84 & 86.72 & 86.75 & 136.52 & 173.35 & 173.40 & 219.78 \\
\hline
\end{tabular}

Validation of the finite element program: In order to check the validity, applicability, and accuracy of the present FE method, many comparisons were performed. The comparisons include theoretical, ANSYS simulation and experimental results.

\section{Comparisons with Theoretical Results}

In Table 3 the non - dimensional critical buckling load is presented in order to compare with References Yu \& Wang (2008); Mohammadi et al., (2009); Mohammadi et al., (2009), for an isotropic plate of material 1 with different aspect ratios. As the Table shows, the present results have a good agreement with References Yu \& Wang (2008); Mohammadi et al., (2009); Mohammadi et al., (2009).

Table 3

Comparison of the non - dimensional critical buckling load $\overline{\mathrm{P}}=\mathrm{Pa}^{2} / \mathrm{D}$ for an isotropic plate (material 1)

\begin{tabular}{ccccc}
\hline Aspect Ratio & \multicolumn{4}{c}{ References } \\
\cline { 2 - 5 } a/b & Ref. [162] & Ref. [163] & Ref. [164] & Present Study \\
\hline 0.5 & 12.33 & 12.3370 & 12.3370 & 12.3 \\
1.0 & 19.74 & 19.7392 & 19.7392 & 19.7 \\
\hline
\end{tabular}

Table 4 below shows the effect of plate aspect ratio and modulus ratio on non - dimensional critical loads $\bar{P}=$ $P\left(b^{2} \pi^{2} / D_{22}\right)$ of rectangular laminates under biaxial compression. The following material properties were used: material 2: $E_{1} / E_{2}=5,10,20,25$ and $40 ; G_{12}=G_{13}=G_{23}=0.5 E_{2} ; v_{12}=0.25$ and $a / h=20$. It is observed that the non - dimensional buckling load increases for symmetric laminates as the modular ratio increases. The present results were compared with Mahmoud Yassin Osman \& Osama Mohammed Elmardi Suleiman (2017) and Reddy (2004). The verification process showed good agreement especially as the aspect ratio increases and the modulus ratio decreases.

Table 4

Buckling load for (0/ 90/ 90/ 0) simply supported (SS) plate for different aspect and moduli ratios under biaxial compression (material 2)

\begin{tabular}{ccccccc}
\hline \multirow{2}{*}{ Aspect Ratio a/b } & Modular Ratio & \multicolumn{5}{c}{ Biaxial Compression } \\
\cline { 2 - 7 } & $E_{1} / E_{2}$ & 5 & 10 & 20 & 25 & 40 \\
\hline \multirow{2}{*}{0.5} & Present & 10.864 & 12.122 & 13.215 & 13.726 & 14.000 \\
& Ref. [165] & - & 12.307 & - & 13.689 & - \\
\hline
\end{tabular}




\begin{tabular}{ccccccc}
\hline & Ref. [166] & 11.120 & 12.694 & 13.922 & 14.248 & 14.766 \\
& Present & 2.790 & 3.130 & 3.430 & 3.510 & 3.645 \\
& Ref. [165] & - & 3.137 & - & 3.502 & - \\
& Ref. [166] & 2.825 & 3.174 & 3.481 & 3.562 & 3.702 \\
& Present & 1.591 & 1.602 & 1.611 & 1.613 & 1.617 \\
& Ref. [165] & - & 1.605 & - & 1.606 & - \\
& Ref. [166] & 1.610 & 1.624 & 1.634 & 1.636 & 1.641 \\
\hline
\end{tabular}

Table 5 shows the effect of plate aspect ratio and modulus ratio on non - dimensional critical buckling loads $\bar{P}=$ $P\left(b^{2} / \pi^{2} D_{22}\right)$ of simply supported (SS) antisymmetric cross - ply rectangular laminates under biaxial compression. The properties of material 2 were used. It is observed that the non - dimensional buckling load decreases for antisymmetric laminates as the modulus ratio increases. The present results were compared with Reddy Reddy (2004). The validation process showed good agreement especially as the aspect ratio increases and the modulus ratio decreases.

Table 5

Buckling load for (0/ 90/ 90/ 0) simply supported (SS) plate for different aspect and moduli ratios under biaxial compression (material 2)

\begin{tabular}{|c|c|c|c|c|c|c|}
\hline \multirow{2}{*}{$\begin{array}{c}\text { Aspect } \\
\text { Ratio a/b }\end{array}$} & \multirow{2}{*}{$\begin{array}{l}\text { Modular } \\
\text { Ratio } \\
E_{1} / E_{2}\end{array}$} & \multicolumn{5}{|c|}{ Biaxial Compression } \\
\hline & & 5 & 10 & 20 & 25 & 40 \\
\hline \multirow[t]{2}{*}{0.5} & Present & 4.000 & 3.706 & 3.535 & 3.498 & 3.442 \\
\hline & Ref. [166] & 3.764 & 3.325 & 3.062 & 3.005 & 2.917 \\
\hline \multirow[t]{2}{*}{1.0} & Present & 1.395 & 1.209 & 1.102 & 1.079 & 1.045 \\
\hline & Ref. [166] & 1.322 & 1.095 & 0.962 & 0.933 & 0.889 \\
\hline \multirow[t]{2}{*}{1.5} & Present & 1.069 & 0.954 & 0.889 & 0.875 & 0.853 \\
\hline & Ref. [166] & 1.000 & 0.860 & 0.773 & 0.754 & 0.725 \\
\hline
\end{tabular}

Table 6 below shows the effect of plate aspect ratio, and modulus ratio on non - dimensional critical buckling loads of simply supported (SS) antisymmetric angle-ply rectangular laminates under biaxial compression.

The properties of material 2 were used. It is observed from Table 6 that the prediction of the buckling loads by the present study is closer to that of Mahmoud Yassin Osman \& Osama Mohammed Elmardi Suleiman (2017) and Reddy Reddy (2004).

Table 6

Buckling load for antisymmetric angle-ply $(45 /-45)_{4}$ plate with different moduli and aspect ratios under biaxial compression (material 2)

\begin{tabular}{cccccc}
\hline \multirow{2}{*}{ Aspect Ratio a/b } & Modular Ratio & \multicolumn{4}{c}{ Biaxial Compression } \\
\cline { 2 - 6 } & $E_{1} / E_{2}$ & 10 & 20 & 25 & 40 \\
\hline \multirow{3}{*}{0.5} & Present & 19.376 & 36.056 & 44.400 & 69.440 \\
& Ref. [165] & 19.480 & - & 44.630 & - \\
& Ref. [166] & 18.999 & 35.076 & 43.110 & 67.222 \\
\multirow{2}{*}{1.0} & Present & 9.028 & 17.186 & 21.265 & 33.512 \\
& Ref. [165] & 9.062 & - & 21.345 & - \\
& Ref. [166] & 8.813 & 16.660 & 20.578 & 32.343 \\
1.5 & Present & 6.144 & 11.596 & 14.322 & 22.013 \\
& Ref. [165] & 6.170 & - & 14.383 & - \\
& Ref. [166] & 6.001 & 11.251 & 13.877 & 21.743 \\
\hline
\end{tabular}

In Tables 7 and 8, the buckling loads for symmetrically laminated composite plates of layer orientation (0/90/90/ 0$)$ have been determined for three different aspect ratios ranging from 0.5 to 1.5 and two modulus ratios 40 and 5 of material 2. It is observed that the buckling load increases with increasing aspect ratio for biaxial compression loading. The buckling load is maximum for clamped-clamped (CC), and clamped - simply supported (CS) boundary 
conditions, while the minimum for simply - simply supported (SS) boundary conditions. It is seen from Tables 7 and 8 that the values of buckling loads by the present study is much closer to the of Mahmoud Yassin Osman \& Osama Mohammed Elmardi Suleiman (2017).

Table 7

Buckling load for $(0 / 90 / 90 / 0)$ plate with different boundary conditions and aspect ratios under biaxial compression $\left(\overline{\mathrm{P}}=\mathrm{Pa}^{2} / \mathrm{E}_{1} \mathrm{~h}^{3}\right)($ material 2$) \mathrm{E}_{1} / \mathrm{E}_{2}=40 ; \mathrm{G}_{12}=\mathrm{G}_{13}=\mathrm{G}_{23}=0.5 \mathrm{E}_{2} ;$ and $v_{12}=0.25$

\begin{tabular}{ccccc}
\hline \multirow{2}{*}{ Aspect Ratio a/b } & Comparisons of & \multicolumn{3}{c}{ Boundary Conditions } \\
\cline { 3 - 5 } & Results & CC & SS & CS \\
\hline \multirow{2}{*}{0.5} & Present & 1.0742 & 0.4143 & 0.9679 \\
& Ref. [165] & 1.0827 & 0.4213 & 1.0022 \\
1.0 & Present & 1.3795 & 0.4409 & 1.0723 \\
& Ref. [165] & 1.3795 & 0.4411 & 1.0741 \\
\multirow{2}{*}{1.5} & Present & 1.6402 & 0.4400 & 1.2543 \\
& Ref. [165] & 1.6367 & 0.4391 & 1.2466 \\
\hline
\end{tabular}

Table 8

Buckling load for $(0 / 90 / 90 / 0)$ plate with different boundary conditions and aspect ratios $\left(\overline{\mathrm{P}}=\mathrm{Pa}^{2} / \mathrm{E}_{1} \mathrm{~h}^{3}\right)($ material 2) $\mathrm{E}_{1} / \mathrm{E}_{2}=5 ; \mathrm{G}_{12}=\mathrm{G}_{13}=\mathrm{G}_{23}=0.5 \mathrm{E}_{2} ;$ and $v_{12}=0.25$

\begin{tabular}{ccccc}
\hline \multirow{2}{*}{ Aspect Ratio a/b } & Comparisons of & \multicolumn{3}{c}{ Boundary Conditions } \\
\cline { 3 - 5 } & Results & CC & SS & CS \\
\hline \multirow{2}{*}{0.5} & Present & 1.7786 & 0.6787 & 1.6325 \\
& Ref. [165] & 1.8172 & 0.6877 & 1.6838 \\
1.0 & Present & 2.1994 & 0.6972 & 1.8225 \\
& Ref. [165] & 2.2064 & 0.6985 & 1.8328 \\
1.5 & Present & 2.7961 & 0.8943 & 1.7643 \\
& Ref. [165] & 2.8059 & 0.8962 & 1.7618 \\
\hline
\end{tabular}

The same behavior of buckling load applies to symmetrically laminated composite plates $(0 / 90 / 0)$ as shown in Tables 9 and 10.

Table 9

Buckling load for $(0 / 90 / 0)$ plate with different boundary conditions and aspect ratios $\left(\overline{\mathrm{P}}=\mathrm{Pa}^{2} / \mathrm{E}_{1} \mathrm{~h}^{3}\right)$ (material 2) $\mathrm{E}_{1} / \mathrm{E}_{2}=40 ; \mathrm{G}_{12}=\mathrm{G}_{13}=\mathrm{G}_{23}=0.5 \mathrm{E}_{2} ;$ and $v_{12}=0.25$

\begin{tabular}{ccccc}
\hline \multirow{2}{*}{ Aspect Ratio a/b } & Comparisons of & \multicolumn{3}{c}{ Boundary Conditions } \\
\cline { 3 - 5 } & Results & CC & SS & CS \\
\hline \multirow{2}{*}{0.5} & Present & 1.7471 & 0.3238 & 0.6870 \\
& Ref. [165] & 0.7529 & 0.3325 & 0.7201 \\
1.0 & Present & 0.9523 & 0.3485 & 0.7925 \\
& Ref. [165] & 0.9511 & 0.3489 & 0.7932 \\
\multirow{2}{*}{1.5} & Present & 1.1811 & 0.3530 & 0.8190 \\
& Ref. [165] & 1.1763 & 0.3514 & 0.8099 \\
\hline
\end{tabular}

Table 10

Buckling load for $(0 / 90 / 0)$ plate with different boundary conditions and aspect ratios $\left(\overline{\mathrm{P}}=\mathrm{Pa}^{2} / \mathrm{E}_{1} \mathrm{~h}^{3}\right)$ (material 2) $\mathrm{E}_{1} / \mathrm{E}_{2}=5 ; \mathrm{G}_{12}=\mathrm{G}_{13}=\mathrm{G}_{23}=0.5 \mathrm{E}_{2} ;$ and $v_{12}=0.25$

\begin{tabular}{ccccc}
\hline \multirow{2}{*}{ Aspect Ratio a/b } & Comparisons of & \multicolumn{3}{c}{ Boundary Conditions } \\
\cline { 3 - 5 } & Results & CC & SS & CS \\
\hline 0.5 & Present & 1.6947 & 0.6772 & 1.5842 \\
& Ref. [165] & 1.7380 & 0.6871 & 1.6337 \\
1.0 & Present & 2.1669 & 0.6970 & 1.7009 \\
\hline
\end{tabular}




\begin{tabular}{ccccc}
\hline \multirow{4}{*}{1.5} & Ref. [165] & 2.1744 & 0.6984 & 1.7113 \\
& Present & 2.5008 & 0.8224 & 1.7658 \\
& Ref. [165] & 2.5075 & 0.8235 & 1.7622 \\
\hline
\end{tabular}

\section{Comparisons with the Results of Ansys Package}

ANSYS is a general-purpose finite element modeling package for numerically solving a wide variety of mechanical problems. These problems include static/ dynamic structural analysis (both linear and non - linear), heat transfer and fluid problems, as well as acoustic and electromagnetic problems. The problem of buckling in ANSYS is considered a static analysis. To validate the present results with ANSYS, the present results were converted from its non dimensional form to the dimensional form by using the formula $\bar{P}=P a^{2} / E_{1} h^{3}$. The E - glass/ Epoxy material is selected to obtain the numerical results for the comparisons. The mechanical properties of this material (material 3 ) is given in Table 11 below.

Table 11

Mechanical Properties of the E - glass/ Epoxy material (material 3)

\begin{tabular}{cc}
\hline Property & Value \\
\hline$E_{1}$ or $E_{x}$ & $38.6 \mathrm{GN} / \mathrm{m}^{2}$ \\
$E_{2}$ or $E_{y}$ & $8.27 \mathrm{GN} / \mathrm{m}^{2}$ \\
$G_{12}$ or $G_{x y}$ & $4.14 \mathrm{GN} / \mathrm{m}^{2}$ \\
$G_{13}$ or $G_{x z}$ & $4.14 \mathrm{GN} / \mathrm{m}^{2}$ \\
$G_{23}$ or $G_{y z}$ & $3.4 \mathrm{GN} / \mathrm{m}^{2}$ \\
$v_{12}$ or $v_{x y}$ & 0.28 \\
\hline
\end{tabular}

Tables 12 to 15 shows comparisons between the results of the present study and that simulated by ANSYS technique. Table 12 shows the effect of boundary conditions on dimensional buckling loads of symmetric angle-ply (30/ -30/ $30 / 30)$ of square thin laminates $(a / h=20)$ under biaxial compression. The properties of material 3 in Table 11 were used. Small differences were shown between the results of the two techniques. The difference ranges between $0.6 \%$ to less than $2 \%$. It is observed that as the mode serial number increases, the difference increases. The same behavior of buckling load of both techniques applies to symmetrically laminated composite plates of the order (45/ 45/ -45/45), (60/-60/-60/60) and (0/ 90/ 90/ 0) shown in Tables 13, 14 and 15.

Table 12

Dimensional buckling load of symmetric angle-ply (30/-30/ -30/ 30) square thin laminates with different boundary conditions $(\mathrm{a} / \mathrm{h}=20)$ (material 3$)$

\begin{tabular}{ccccc}
\hline $\begin{array}{c}\text { Boundary } \\
\text { Conditions }\end{array}$ & Method & \multicolumn{3}{c}{ Mode Serial Number } \\
& & 1 & 2 & 3 \\
\hline SS & Present & $109.5 \mathrm{~N}$ & $193.4 \mathrm{~N}$ & $322.8 \mathrm{~N}$ \\
& ANSYS & $109.4 \mathrm{~N}$ & $206.5 \mathrm{~N}$ & $315.8 \mathrm{~N}$ \\
CS & Present & $234.7 \mathrm{~N}$ & $257.2 \mathrm{~N}$ & $371.41 \mathrm{~N}$ \\
& ANSYS & $233.21 \mathrm{~N}$ & $255.6 \mathrm{~N}$ & $378.7 \mathrm{~N}$ \\
\hline
\end{tabular}

Table 13

Dimensional buckling load of symmetric angle-ply (45/-45/-45/45) square thin laminates with different boundary conditions $(\mathrm{a} / \mathrm{h}=20)$ (material 3$)$

\begin{tabular}{lllcc}
\hline \multirow{2}{*}{$\begin{array}{c}\text { Boundary } \\
\text { Conditions }\end{array}$} & \multirow{2}{*}{ Method } & \multicolumn{3}{c}{ Mode Serial Number } \\
\cline { 3 - 5 } & & \multicolumn{1}{c}{1} & 2 & \multicolumn{1}{c}{3} \\
\hline SS & Present & $115.24 \mathrm{~N}$ & $219.5 \mathrm{~N}$ & $305.4 \mathrm{~N}$ \\
& ANSYS & $116.3 \mathrm{~N}$ & $225.5 \mathrm{~N}$ & $312.7 \mathrm{~N}$ \\
$\mathrm{CS}$ & Present & $196.33 \mathrm{~N}$ & $282.8 \mathrm{~N}$ & $439.53 \mathrm{~N}$ \\
& ANSYS & $194.7 \mathrm{~N}$ & $287.6 \mathrm{~N}$ & $444.51 \mathrm{~N}$ \\
\hline
\end{tabular}


Table 14

Dimensional buckling load of symmetric angle-ply (60/-60/-60/60) square thin laminates with different boundary conditions $(\mathrm{a} / \mathrm{h}=20)$ (material 3)

\begin{tabular}{llccc}
\hline Boundary & \multirow{2}{*}{ Method } & \multicolumn{3}{c}{ Mode Serial Number } \\
\cline { 3 - 5 } Conditions & & 1 & 2 & \multicolumn{1}{c}{3} \\
\hline SS & Present & $109.39 \mathrm{~N}$ & $193.213 \mathrm{~N}$ & $322.19 \mathrm{~N}$ \\
& ANSYS & $109.6 \mathrm{~N}$ & $191.13 \mathrm{~N}$ & $325.37 \mathrm{~N}$ \\
$\mathrm{CS}$ & Present & $161.4 \mathrm{~N}$ & $279.1 \mathrm{~N}$ & $370.5 \mathrm{~N}$ \\
& ANSYS & $160.6 \mathrm{~N}$ & $280.4 \mathrm{~N}$ & $377.7 \mathrm{~N}$ \\
\hline
\end{tabular}

Table 15

Dimensional buckling load of symmetric cross-ply (0/90/90/0) square thin laminates with different boundary conditions $(\mathrm{a} / \mathrm{h}=20)($ material 3$)$

\begin{tabular}{ccccc}
\hline \multirow{2}{*}{$\begin{array}{c}\text { Boundary } \\
\text { Conditions }\end{array}$} & \multirow{2}{*}{ Method } & \multicolumn{3}{c}{ Mode Serial Number } \\
\cline { 3 - 5 } & & 1 & 2 & 3 \\
\hline SS & Present & $93.4 \mathrm{~N}$ & $170.4 \mathrm{~N}$ & $329 \mathrm{~N}$ \\
& ANSYS & $94.4 \mathrm{~N}$ & $181.4 \mathrm{~N}$ & $315 \mathrm{~N}$ \\
CS & Present & $244.5 \mathrm{~N}$ & $263.7 \mathrm{~N}$ & $366.23 \mathrm{~N}$ \\
& ANSYS & $244.4 \mathrm{~N}$ & $265.8 \mathrm{~N}$ & $369.6 \mathrm{~N}$ \\
\hline
\end{tabular}

\section{Comparisons with Experimental Results}

Many numerical and mathematical models exist which can be used to describe the behavior of a laminate under the action of different forces. When it comes to buckling, a mathematical model can be developed which is used to model the phenomenon of buckling. But numerical methods become complicated as the number of assumptions and variables increase. Also, once the model is formed, it takes a lot of time to solve the partial differential equations and then arrive at the final result. This process becomes very cumbersome and time-consuming. In view of the abovementioned limitations, experimental methods are followed. The experimental process needs less time and less computational work. Also, the results obtained in experiments are fairly close to that which is obtained theoretically.

The composites have two components. The first is the matrix which acts as the skeleton of the composite and the second is the hardener which acts as the binder for the matrix. The reinforcement that was used for the present study was woven glass fibers. Glass fibers are materials which consist of numerous extremely fine fibers of glass. The hardener that utilized was epoxy which functions as a solid cement to keep fiber layers together.

To manufacture the composites the following steps were taken:

1) The weight of the fiber was noted down, then the approximately $1 / 3^{\text {rd }}$ mass of epoxy was prepared for further use.

2) A clean plastic sheet was taken and the mold releasing spray was sprayed on it. After that, a generous coating of the hardener mixture was coated on the sheet. A woven fiber sheet was taken and placed on top of the coating. A second coating was done again, and the second layer of fiber was placed, and the process continued until the required thickness was obtained. The fiber was pressed with the help of rollers.

3) Another plastic sheet was taken and the mold releasing spray was sprayed on it. The plastic sheet was placed on top of the fiber with hardener coating.

4) The plate obtained was placed under weights for a period of 24 hours.

5) After that, the plastic sheets were removed and the plates separated.

The buckling test rig for biaxial compression was developed in Tehran University of Science and Technology, College of Engineering, Iran. The frame was built using rectangular shaped mild steel channels. The channels were welded to one another and then the frame was prepared. Two-Ton hydraulic jacks were assembled into the frame to provide the necessary hydraulic forces for biaxial compression of the plates. The setup can be easily assembled and disassembled. Thus, the setup offers flexibility over the traditional buckling setups.

It is proposed to undertake some study cases and obtain experimental results of non - dimensional buckling of rectangular laminated plates subjected to in-plane biaxial Compressive loads. The plates are assumed to be either simply supported on all edges (SS), or a combined case of clamped and simply supported (CS), or clamped on all edges (CC). 
The effects of various parameters like material anisotropy, fiber orientation, aspect ratio, and edge conditions on the buckling load of laminated plates are to be investigated and compared with the present finite element results. The plates are made of graphite - epoxy material (material 3) and generally, square with side $a=b=250 \mathrm{~mm}$ and length to thickness ratio $(a / h)=20$. The required experiments are explained below:

\section{Experiment (1): effect of material anisotropy $\left(E_{1} / E_{2}\right)$}

Cross-ply symmetric laminates with length to thickness ratio of $(a / h=20)$ are to be tested. The ratio of longitudinal to transverse modulus $\left(E_{1} / E_{2}\right)$ is to be increased from 10 to 50 . The required number of plies is 8 . The plate is simply - supported (SS) on all edges. The experimental values of bucthe kling load were compared with the present theoretical results as shown in Table 16.

Table 16

Effect of material anisotropy on buckling load, $\mathrm{a} / \mathrm{h}=20$

\begin{tabular}{ccc}
\hline$E_{1} / E_{2}$ & Method & $\begin{array}{c}\text { Buckling } \\
\text { loads }\end{array}$ \\
\hline 10 & Present & 0.5537 \\
& Experimental & 0.4985 \\
20 & Present & 0.4789 \\
& Experimental & 0.4310 \\
30 & Present & 0.4536 \\
& Experimental & 0.4082 \\
40 & Present & 0.4418 \\
& Experimental & 0.3976 \\
50 & Present & 0.4343 \\
& Experimental & 0.3908 \\
\hline
\end{tabular}

It is observed that the buckling load decreases with the increase in material anisotropy $\left(E_{1} / E_{2}\right)$. The present theoretical results were about $10 \%$ higher than the experimental values which is considered to be acceptable.

\section{Experiment (2): effect of fiber orientation $(\theta)$}

Symmetric and antisymmetric cross-ply laminated plates $(0 / 90 / 90 / 0)$ and $(0 / 90 / 0 / 90)$ with length to thickness ratio $(a / h)$ are to be tested. The required number of plies is 8 . The plate is simply supported (SS) on four edges. As shown in Table 17 below, the theoretical buckling load was found to be $10 \%$ above the experimental value.

Table 17

Effect of fiber orientation on buckling load, $\mathrm{E}_{1} / \mathrm{E}_{2}=40, \mathrm{a} / \mathrm{h}=20$

\begin{tabular}{lll}
\hline Orientation & Method & Buckling loads \\
\hline Symmetric & Present & 0.4418 \\
& Experimental & 0.3976 \\
Anti - Symmetric & Present & 0.4417 \\
& Experimental & 0.3975 \\
\hline
\end{tabular}

\section{Experiment (3): effect of aspect ratio $(a / b)$}

The effect of aspect ratio $(a / b)$ on the buckling load is studied by testing cross - ply symmetric (0/90/ 90/ 0$)$ laminates with length to thickness ratio $(a / h=20)$. The aspect ratios $0.5,1,1.5$ and 2.0 are to be tested. The required number of plies is 8 . The plate is simply supported on four edges and the modulus ratio is taken to be $\left(E_{1} / E_{2}=40\right)$. As shown in Table 18 below, the difference between the theoretical and experimental buckling was found to be about $10 \%$. 
Table 18

Effect of aspect ratio on buckling load, $E_{1} / E_{2}=40, a / h=20$

\begin{tabular}{ccc}
\hline $\begin{array}{c}\text { Aspect Ratio } \\
(a / b)\end{array}$ & Method & Buckling loads \\
\hline 0.5 & Present & 0.4192 \\
& Experimental & 0.3773 \\
1.0 & Present & 0.4418 \\
& Experimental & 0.3976 \\
1.5 & Present & 0.7187 \\
& Experimental & 0.6468 \\
2.0 & Present & 1.2324 \\
& Experimental & 1.1092 \\
\hline
\end{tabular}

\section{Experiment (4): Effect of Boundary Conditions}

Cross-ply symmetric laminates $(0 / 90 / 90 / 0)$ can be used to study the effect of the boundary conditions on the buckling load. The length to thickness ratio is taken to be $(a / h=20)$. The boundary conditions used are SS, CS and CC. The required number of plies is 8 and the modulus ratio $\left(E_{1} / E_{2}\right)$ is selected to be 40 . As shown in Table 19 below, the same difference between the theoretical and experimental results was observed.

Table 19

Effect of boundary conditions on buckling load, $E_{1} / E_{2}=40, a / h=20$

\begin{tabular}{ccc}
\hline $\begin{array}{c}\text { Boundary } \\
\text { Conditions }\end{array}$ & Method & Buckling loads \\
\hline SS & Present & 0.4418 \\
& Experimental & 0.3976 \\
$\mathrm{CS}$ & Present & 1.2882 \\
& Experimental & 1.1594 \\
$\mathrm{CC}$ & Present & 1.3812 \\
& Experimental & 1.2431 \\
\hline
\end{tabular}

\section{Conclusions}

The finite element model has been formulated to compute the buckling loads of laminated plates with rectangular cross-section. To verify the accuracy of the present technique, buckling loads are evaluated and validated with other works available in the literature. Further comparisons were carried out and compared with the results obtained by the ANSYS package and experimental results. The good agreement with available data demonstrates the reliability of the finite element method used.

\section{Acknowledgment}

The authors would like to acknowledge with deep thanks and profound gratitude Mr. Osama Mahmoud of Daniya Center for Publishing and Printing Services, Atbara, Sudan who spent many hours in editing, re-editing of the manuscript in compliance with the standard format of International Journal of Physical Sciences and Engineering (IJPSE). 


\section{References}

Aalami, B. (1972). Large deflection of elastic plates under patch loading. Journal of the Structural Division, 98(Proc Paper 9359).

Arauz, WMS, Gámez, MR, Pérez, AV, Castillo, GAL, \& Alava, LAC (2017). The future of micro-grids in Ecuador. International Journal of Physical Sciences and Engineering, 1 (3), 18. https://doi.org/10.21744/ijpse.v1i3.53

Bouazza, M., Ouinas, D., Yazid, A., \& Hamouine, A. (2012). Buckling of thin plates under uniaxial and biaxial compression. Journal of Materials Science and Engineering. A, 2(8A), 487.

Cassell, A. C., \& Hobbs, R. E. (1976). Numerical stability of dynamic relaxation analysis of non-linear structures. International Journal for numerical methods in engineering,10(6), 1407-1410. https://doi.org/10.1002/nme.1620100620

Day, A. S. (1965). 'An introduction to dynamic relaxation', the engineer, vol. 219.

Elmardi, O. M. (2014). Verification of dynamic relax-ation method in isotropic, orthotropic and laminated plates using small deflection theory. International Journal of Advanced Science and Technology, 72(4), 37-48.

Gamez, MR, Perez, AV, Sera, AS, \& Ronquillo, ZM (2017). Renewable energy sources and local development. International Journal of Social Sciences and Humanities, I (2), 1019. https://doi.org/10.29332/ijssh.v1n2.31

González, AED, Arauz, WMS, Gamez, MR, \& Alava, LAC (2017). Photovoltaic energy to face an earthquake. International Journal of Physical Sciences and Engineering, I(3), 1930. https://doi.org/10.21744/ijpse.v1i3.61

John, V. (1992). Introduction to engineering materials. Macmillan International Higher Education.

Mohammadi, M., Saidi, A. R., \& Jomehzadeh, E. (2010). Levy solution for buckling analysis of functionally graded rectangular plates. Applied Composite Materials, 17(2), 81-93. https://doi.org/10.1007/s10443-009-9100-z

Mohammed Al-Sulha Sulaiman, Osama, and Mohammed Mohammed Elmardi Suleiman Khayal. "Nonlinear Analysis of Rectangular Laminated Plates Using Large Deflection Theory." (2017).

Osman, M. Y., \& Suleiman, O. M. E. (2017). Buckling analysis of thin laminated composite plates using finite element method. International Journal of Engineering Research and Advanced Technology, 3.

Putcha, N. S., \& Reddy, J. N. (1986). A refined mixed shear flexible finite element for the nonlinear analysis of laminated plates.

Reddy, J. N. (2004). Mechanics of laminated composite plates and shells: theory and analysis. CRC press. https://doi.org/10.1201/b12409

Rushton, K. R. (1968). Large deflexion of variable-thickness plates. International Journal of mechanical sciences, 10(9), 723-735. https://doi.org/10.1016/0020-7403(68)90086-6

Setoodeh, A. R., \& Karami, G. (2004). Static, free vibration and buckling analysis of anisotropic thick laminated composite plates on distributed and point elastic supports using a 3-D layer-wise FEM. Engineering structures, 26(2), 211-220.

Suleiman, O. M. E. (2016). Text Book on Dynamic Relaxation Method. Lap Lambert Academic Publishing, Germany, and ISBN:(978-3-659-94751-3).

Suleiman, O. M. E. (2017). Deflection of laminated composite plates using dynamic relaxation method. International Journal of Physical Sciences and Engineering, 1(1), 40-53. https://doi.org/10.21744/ijpse.v1i1.5

Turvey, G. J., \& Osman, M. Y. (1989). Large deflection analysis of orthotropic Mindlin plates'. In Proceedings of the 12th energy resources technical conference and Exhibition, Houston, Texas (pp. 163-172).

Turvey, G. J., \& Osman, M. Y. (1990). Elastic large deflection analysis of isotropic rectangular Mindlin plates. International journal of mechanical sciences, 32(4), 315-328. https://doi.org/10.1016/00207403(90)90096-2

Turvey, G. J., \& Osman, M. Y. (1991). Large deflection effects in antisymmetric cross-ply laminated strips and plates. In Composite Structures (pp. 397-413). Springer, Dordrecht. https://doi.org/10.1007/978-94-011-36624_31

Whitney, J. M., \& Pagano, N. J. (1970). Shear deformation in heterogeneous anisotropic plates. Journal of applied mechanics, 37(4), 1031-1036.

Yang, P. C., Norris, C. H., \& Stavsky, Y. (1966). Elastic wave propagation in heterogeneous plates. International Journal of solids and structures, 2(4), 665-684. https://doi.org/10.1016/0020-7683(66)90045-X

Yu, L. H., \& Wang, C. Y. (2008). Buckling of rectangular plates on an elastic foundation using the Levy method. AIAA journal, 46(12), 3163-3167. 